\title{
Effects of Exposure to Total Particulate Matter of Cashew Nuts Shell in the Respiratory System of Mice with Chronic Obstructive Pulmonary Disease
}

\author{
${ }^{1}$ Fladimir de Lima Gondim, ${ }^{2}$ Gilvan Ribeiro dos Santos, ${ }^{2}$ Daniel Silveira Serra, ${ }^{3}$ Rinaldo dos Santos Araújo, \\ ${ }^{2}$ Mona Lisa Moura de Oliveira, ${ }^{2}$ Francisco Sales Ávila Cavalcante
}

${ }^{1}$ State University of Ceará, Institute of Biomedical Sciences, Av. Dr. Silas Munguba, 1700, zip: 60714-903, Fortaleza, Brazil.

${ }^{2}$ State University of Ceará, Center of Technological Sciences, Av. Dr. Silas Munguba, 1700, zip: 60714-903, Fortaleza, Brazil.

${ }^{3}$ Federal Institute of Ceará, Fortaleza, Brazil.

Correspondence Author: Fladimir de Lima Gondim, State University of Ceará, Institute of Biomedical Sciences, Av. Dr. Silas Munguba, 1700, zip: 60714-903, Fortaleza, Brazil

E-mail: fladimirgondim@gmail.com

Received date: 11 December 2018, Accepted date: 22 Janaury 2019, Online date: 29 January 2019

Copyright: (C) 2019 Fladimir de Lima Gondim et al, This is an open-access article distributed under the terms of the Creative Commons Attribution License, which permits unrestricted use, distribution, and reproduction in any medium, provided the original author and source are credited.

\begin{abstract}
About 3 billion people are exposed to biomass fuel smoke compared to 1.1 billion people who smoke tobacco, suggesting that exposure to biomass smoke may be the most important global risk factor for Chronic obstructive pulmonary diseases COPD. Due to the increasing use of residual biomass as an energy source, there is a need to investigate the effects of exposure to total particulate matter from combustion exhaust gases from cashew nut shells (CNS) in more susceptible population groups. Thus, in the present study, we sought to investigate the effects of exposure to TPM of SNC in the Respiratory System of mice with COPD. To perform this investigation, C57black/6 mice were exposed to cigarette smoke or ambient air (CTRL group) for 60 days, and after this period the animals were submitted to 20 days of nasal instillation containing TPM (CS+TPM) or saline solution (CS). $24 \mathrm{~h}$ after last instillation, the animals were connected to a ventilator for small animals to perform the analyzes referring to the variables of the respiratory system mechanics. Our results demonstrated changes in all variables analyzed between the CS+TPM, CS and CTRL groups, and there was greater hyperresponsiveness in smooth muscle of the airways, demonstrating that the lung injury of animals caused by exposure to cigarette smoke is greater when associated with exposure to TMP from CNS combustion. In this way, increasing use of this biofuel in industries, craft centers and residences, can be can be harmful, especially to those with pre-existing respiratory disease.
\end{abstract}

Key words: Biomass, cashew nuts shell, chronic obstructive pulmonary disease, particulate matter, respiratory system.

\section{INTRODUCTION}

Global warming is one of the most debated environmental issues today, either because of the need for better knowledge on the subject, or for the analysis of its possible influences on life on earth. The increase in the temperature of the Earth's atmosphere coupled with the increase in the atmospheric levels of carbon dioxide $\left(\mathrm{CO}_{2}\right)$ are issues that need attention from the government and the scientific community, in an attempt to reverse the problems already present, and prevent them from increasing or become irreparable in the near future. One of the causes of global warming is the use of fossil fuels, a non-renewable resource.

Faced with this problem, the search for renewable energies has grown, highlighting the use of residual biomass. Most households in China, India and sub-Saharan Africa use biomass fuel for cooking, and in rural areas of Latin America the proportion ranges from $30 \%$ to $75 \%$ (EZZATI; KAMMEN, 2002). Thus, approximately 3 billion people worldwide are exposed to biomass combustion gases compared to 1.1 billion people who smoke tobacco, suggesting that exposure to biomass smoke may be the most important overall risk factor for chronic obstructive pulmonary disease (COPD) (LOPEZ et al., 2006). As one of the largest agricultural producers in the world, Brazil has great capacity to generate energy from the residual biomass of sugarcane, rice, coffee straw and cashew nut shells (CNS). Despite the use of CNS in boiler feed for thermal energy generation in some industries, the adverse health effects of the exhaust gases from the combustion process of CNS are poorly studied, mainly in analyzes of exposure to people with pre-existing respiratory diseases such as emphysema, characterized as a COPD. 
Although avoidable and treatable, COPD is still the fourth leading cause of death in the world, and it is estimated that there will be an increase in its incidence in the coming decades because of an aging population and an increase in its risk factors, such as irregular physical activity, poor eating habits, smoking and exposure to environmental pollutants (GOLD, 2018; ELWOOD et al., 2013).

It is estimated that about 5.2 million people die each year due to complications caused by smoking (WHO, 2005). In parallel, exposure to particulate matter (PM) is one of the factors most associated with adverse health effects (DOCKERY; HUECKELWENG; BIRBAUMER., 2009). Several studies have demonstrated the harmful effects of pollution and cigarette smoke on health (KENNEDY-FEITOSA et al., 2016; PETRUSCA et al., 2014; MAINALI et al., 2015; LEE et al., 2015; NAKAMURA et al., 2015), however, few investigated the association of these two factors, and we are not aware of studies that show the association between exposure to cigarette smoke and exposure to total particulate matter (TPM) from combustion exhaust gases from CNS. This fact is important because, in general, the acute effects secondary to PM exposure are mainly found in susceptible groups (with previous respiratory disease) and not in healthy populations (DONALDSON; MACNEE, 2001).

In view of the above, and due to the increasing use of residual biomass as an energy source, there is a need to investigate the effects of exposure to TPM from combustion exhaust gases from CNS in more susceptible population groups. Our hypothesis is that acute exposure to atmospheric pollutants, specifically TPM from the combustion of CNS, in individuals from susceptible groups (with pre-existing respiratory disease) may exacerbate the harmful effects on the respiratory system. Thus, in the present study, we sought to investigate the effects of exposure to TPM of SNC in the Respiratory System of mice with COPD. To perform this investigation, we used analyzes of respiratory mechanics in vivo, pulmonary parenchyma histopathology and morphometry in vitro.

\section{MATERIALS AND METHODS}

\section{CNS Combustion System and TPM Collection}

A CNS combustion system was developed to collect TPM from its exhaust gases (Fig. 1). For this collection, the CNS (400 g) were first placed in a cylindrical stainless-steel burner (Fig. 1A). Then, the initial combustion ignition of CNS was performed by supplying liquefied petroleum gas (LPG-Figure 1B) and ambient air from an air compressor (Fig. 1C). The combustion process of the CNS was accompanied by thermocouples (Fig. 1D) and flow transducers (Fig. 1E) connected to a data acquisition system (Field Logger-Figure 1F) for the analysis and control of temperature and LPG and air flows (Unpublished data), transferring the information to a notebook (Fig. 1G). The exhaust gases generated by CNS combustion were directed by a chimney (Fig. 1H) to a system containing 2 glass fiber filters (Fig. 1I), where the flow of $5 \mathrm{~L} / \mathrm{m}$ was maintained by suction pump (AirChek ${ }^{\circledR}$ XR5000Fig. 1J).

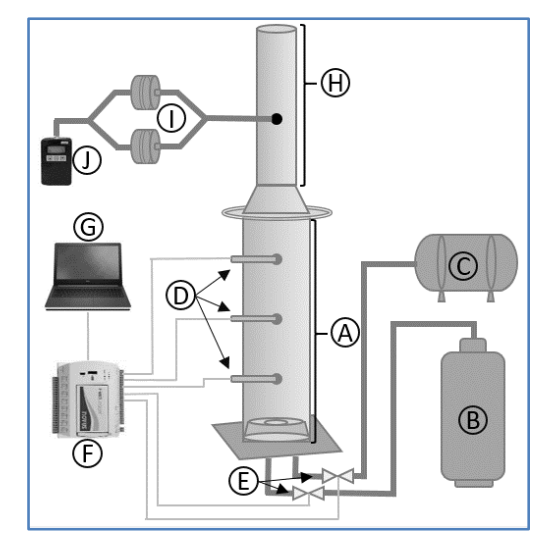

Fig. 1 CNS`s combustion system for collection of TPM. A - Biomass combustion reactor; B - LPG; C - Air compressor; D Thermocouples; E - Flow transducers; F - Data acquisition system (Fieldlogger); G - Notebook; H - Chimney; I - glass fiber filters; J - Suction pump.

\section{Preparation of the aqueous suspensions for intranasal instillation of TPM.}

After collecting the TPM filters from the combustion exhaust gases of the CNS, the cleaned filters were placed in an oven at $50^{\circ} \mathrm{C}$ for 24 hours and weighed on analytical balance (FA-2104N). Then, the CNS combustion process was carried out to collect TPM. Subsequently, the TPM containing filters were put back into the oven at $50^{\circ} \mathrm{C}$ for 24 hours, and again weighed.

The filters were then packed in a Becker containing saline solution and sonicated for 8 hours in an ultrasonic sonicator (Q3350QUIMIS ${ }^{\circledR}$ ). After sonication, the filters were again placed in the oven at $50^{\circ} \mathrm{C}$ for 24 hours and weighed. The efficiency of the extraction of the particles is calculated by the difference between the masses of the filters before and after the collection process (MAATZ et al., 2009). The final particle volume ratio was $1: 1(1 \mu \mathrm{g}: 1 \mu \mathrm{L})$, where we used $30 \mu \mathrm{g}$ of TPM mass in $30 \mu \mathrm{L}$ of the final solution.

\section{Animals}


All animal use and care procedures were previously approved by the animal ethics committee of the State University of Ceará (Protocol No. 0681559/2018). Invasive procedures were performed under anesthesia and every effort was made to minimize suffering.

C57black/6 mice with body mass of $25 \pm 5 \mathrm{~g}$ and access to water and food ad libitum, were used in this study. To study COPD induced by cigarette smoke (CS), mice were exposed to 12 commercial cigarettes per day for 60 days using an inhalation chamber (40 cm long, $30 \mathrm{~cm}$ wide, and $25 \mathrm{~cm}$ high). The animals were placed in the inhalation chamber, housed inside an exhaust hood. The cigarettes were coupled to a $60 \mathrm{~mL}$ plastic syringe, and the CS was sucked into the syringe and then immediately expelled into the inhalation chamber. The animals were kept in this condition, with presence of CS in this environment, for 6 min. Then the inhalation chamber cap was removed, and the exhaust fan connected to evacuate the smoke for 1 min. Exposure to CS was repeated four times ( 4 x $6 \mathrm{~min}$ ) with a 1 min escape interval after each exposure. This procedure was repeated three times a day (8h am, 12h am and 4h pm) (VALENÇA et al., 2008).

We used 24 animals randomly divided into three groups (Fig. 2). In the first group (n=8), the animals were exposed for 60 days to ambient air, and subsequently received intranasal instillation of $30 \mu \mathrm{L}$ of solution from filter sonication in clean glass fiber in saline solution $(0.9 \% \mathrm{NaCl})$ for 20 days (CTRL group). In the second group $(\mathrm{n}=8)$, the animals were submitted to the protocol of exposure to CS for 60 days and received intranasal instillation of $30 \mu \mathrm{L}$ of solution from sonication of the clean glass fiber filter in saline solution for 20 days (CS group). In the third group $(n=8)$, the animals were submitted to the protocol of exposure to CS for 60 days, and received intranasal instillation of $30 \mu \mathrm{g}$ of TPM from the CNS combustion exhaust gases diluted in $30 \mu \mathrm{L}$ of saline solution for 20 days (CS+TPM group).

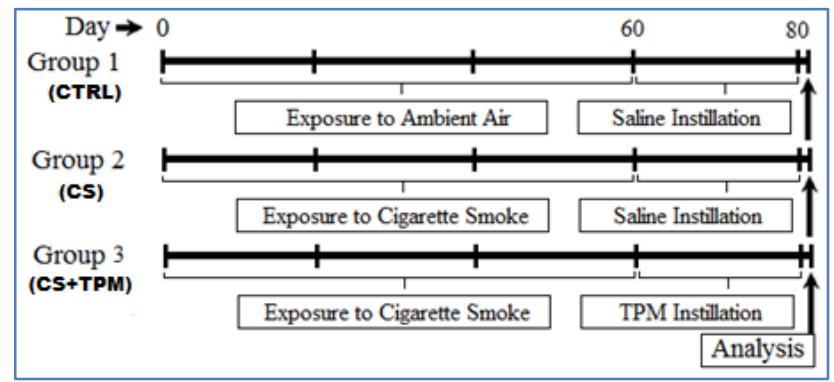

Fig. 2 Schematic diagram of the experimental protocol. In group 1 (CTRL), were exposed for 60 days to ambient air, and subsequently received intranasal instillation of $30 \mu \mathrm{L}$ of solution from filter sonication in clean glass fiber in saline solution $(0.9 \%$ $\mathrm{NaCl}$ ) for 20 days. In group 2 (CS), were submitted to the protocol of exposure to cigarette smoke for 60 days and received intranasal instillation of $30 \mu \mathrm{L}$ of solution from sonication of the clean glass fiber filter in saline solution for 20 days. In group 3 (CS+TPM), were submitted to the protocol of exposure to cigarette smoke for 60 days, and received intranasal instillation of 30 $\mu \mathrm{g}$ of TPM from the CNS combustion exhaust gases diluted in $30 \mu \mathrm{L}$ of saline solution for 20 days. All analyses were performed on day 81 .

\section{Intranasal instillation}

Exposure of the animals to the solution containing TPM (CS+TPM group) or saline solution (CTRL and CS groups) was performed via intranasal instillation during 20 days after protocol of exposure to cigarette smoke or ambiente air (CTRL group). Prior to intranasal instillation, the animals were sedated with sevofluorane (1 alveolar minimum concentration-AMC). The instillation causes a reflex of apnea followed by deep inspiration that leads the fluid into the lung. The animals received instillations containing $30 \mu \mathrm{g}$ of TPM from the CNS combustion exhaust gases, diluted in $30 \mu \mathrm{L}$ of saline solution (CS+TPM group), or $30 \mu \mathrm{L}$ of clean filter fiber filter sonication solution (CTRL and CS groups). The technique used was effective to avoid wastage of the material. All analyzes were performed 24 hours after the last instillation (day 81).

\section{Experimental Protocol}

$24 \mathrm{~h}$ after the last intranasal instillation of saline solution (CTRL and CS groups) or total particulate matter (CS+TPM), the animals were anesthetized with sodium pentobarbital $\left(50 \mathrm{mg} / \mathrm{kg}\right.$, i.p., Hypnol ${ }^{\circledR} 3 \%$, Syntect, Brazil) and tracheotomized. The animals were intubated with a 18-gauge cannula (Eastern Medikit, Delhi, India) that was then connected to a computer-controlled ventilator for small animals (Scirec ${ }^{\circledR}$-flexVent ${ }^{\circledR}$, Montreal, QC, Canada). The animals were ventilated at baseline settings: respiratory frequency of $120 \mathrm{breaths} / \mathrm{min}$, tidal volume of $10 \mathrm{~mL} / \mathrm{kg}$, limiting pressure of $30 \mathrm{cmH}_{2} \mathrm{O}$, and positive end-expiratory pressure (PEEP) of $3 \mathrm{cmH}_{2} \mathrm{O}$. Animals were then paralyzed with pancuronium bromide $(0.5 \mathrm{~mL} / \mathrm{kg}$, i.p., Cristália, Lindoia, MG, Brazil).

Initially we standardized the mechanical history of the respiratory system with two deep inflations (DI, 6-s long, peak pressure: $\left.30 \mathrm{cmH}_{2} \mathrm{O}\right)$. Followed by 5 minutes of ventilation at baseline. Soon after, the impedance of the respiratory system $\left(Z_{r s}\right)$ was measured with the forced oscillation technique (HANTOS et al., 1992), 12 sequential $30 \mathrm{~s}$ sampling intervals, for a total of 6 minutes (BATES, 2009).

The experimental $Z_{r s}$ was fitted to the constant phase model as previously described (HIRAI et al., 1999):

$Z_{r s}=R_{N}+I(2 \pi f) i+\frac{G-H i}{(2 \pi f)^{\alpha}}$ 
$\alpha=\frac{2}{\pi} \tan ^{-1}\left(\frac{H}{G}\right)$

where $R_{N}$ is the Newtonian resistance, which represents the central airways resistance, $i=\sqrt{-1}, f$ is the frequency (Hz), $I$ represents airway inertance, and $G$ and $H$ are respectively the dissipative and elastic properties of lung tissue (HANTOS et al., 1992).

Thereafter, starting at the functional residual capacity (FRC) defined by the PEEP, the flexiVent delivered 7 inspiratory pressure steps for a total pressure of $30 \mathrm{cmH}_{2} \mathrm{O}$, followed by 7 expiratory steps, pausing at each step for $1 \mathrm{~s}$. At each step plateau pressure $(P)$ was recorded and related to the total volume $(V)$ delivered to produce a quasi-static PV (pressure-volume) curve. Static compliance $\left(C_{S T}\right)$ was calculated as the slope of the curve (SALAZAR; KNOWLES, 1964). Two quasi-static PV curves were obtained to measure $C_{S T}$, an estimate of inspiratory capacity $(I C)$, and PV loop area. Another forced oscillation technique ensued to determine respiratory system mechanics.

\section{Methacholine challenge}

Immediately after measurements of respiratory system mechanics, two DI were done, followed by 5 min of ventilation with baseline settings. Airway smooth muscle hyperresponsiveness was evaluated by inhalation of methacholine (MCh) (SigmaAldrich, St.Louis, MI, USA) delivered by aerosol produced by an ultrasonic nebulizer (Inalasonic, NS, São Paulo, Brazil) coupled to the inspiratory line of the ventilator. For such purpose, $4 \mathrm{~mL}$ of $\mathrm{MCh}$ solution $(30 \mathrm{mg} / \mathrm{mL})$ were added to the nebulizer container. The nebulization was carried out during $30 \mathrm{~s}$ under mechanical ventilation (XUE et al., 2019) and the average amount delivered to the animal was $1.2 \mathrm{mg} / \mathrm{kg}$ of $\mathrm{MCh}$ solution. After nebulization, the same previous analysis was repeated (forced oscillation, 30-s sequential intervals for $6 \mathrm{~min}$ ), followed by two DI and another forced oscillation data gathering.

\section{Histological study}

Immediately after the determination of respiratory system mechanics, the rib cage was opened and Heparin (1000 IU) was injected in right ventricle of the heart. The trachea was clamped at end-expiration, and the abdominal aorta and vena cava were sectioned, yielding a massive hemorrhage that quickly euthanized the animals. The lungs were perfused with saline and, then, removed en bloc. The right lung was isolated, frozen in liquid nitrogen, and stored for biochemistry analysis; the left lung was kept at functional residual capacity and fixed in Millonig's formaldehyde (100 mL HCHO, $900 \mathrm{~mL} \mathrm{H2O,} 18.6 \mathrm{~g} \mathrm{NaH2PO} 4,4.2 \mathrm{~g}$ $\mathrm{NaOH}$ ). Slides containing left lung sections were stained with hematoxylin and eosin (HE) and examined by optical microscopy according to their qualitative and quantitative aspects. An investigator, who was unaware of the origin of the coded material, examined the samples microscopically.

Quantitative analysis was performed using an integrated eyepiece with a coherent system consisting of a 100-point and 50line grid coupled to a conventional light microscope. The fraction area of collapsed alveoli or normal pulmonary areas, and the amount of polymorphonuclear (PMN) cells, as well as pulmonary tissue were determined by the pointcounting technique (WEIBEL, 1990). The air-space enlargement was quantified by the mean linear intercept length of the distal air spaces $\left(L_{m}\right)$ in 30 randomly chosen fields of tissue sections per group (KNUDSEN et al., 2010).

Cellularity was assessed at 1000x magnification across 10-15 random non-coincident microscopic fields in each animal. Morphometric analysis and determination of bronchoconstriction index were done at 400× magnification. The bronchoconstriction index (BCI) was determined in 10 non-coincident microscopic fields per animal by counting the number of points in the airway lumen (NP) and intercepts through the airway wall (NI) using a reticulum and applying the equation:

$\mathrm{IBC}=\frac{\mathrm{NI}}{\sqrt{\mathrm{NP}}}$

\section{Statistical analysis}

Statistical analyses were performed using GraphPad Prism version 5.00 (GraphPad, San Diego, CA, USA). The pulmonary function data are presented as mean $\pm \mathrm{SD}$, where $n$ represents the number of samples. Data normal distribution and homogeneities of variances were tested with Kolmogorov-Smirnov (with Lilliefors's correction) and Levene median tests, respectively. If both conditions were satisfied, Student's t-test was used. If any condition was refused, Mann-Whitney non-parametric test was used instead. A difference was considered significant if $p<0.05$.

\section{RESULTS}

Our results concerning the analysis of respiratory system impedance $\left(Z_{r s}\right)$, calculated from the forced oscillation technique, are presented in Figure 3. Some comparisons between the variables related to airway resistance $\left(R_{N}\right)$, tissue resistance $(G)$ and tissue elastance $(H)$ of CTRL, CS and CS+TPM groups presented statistically significant differences $(\mathrm{p}<0.05)$. 


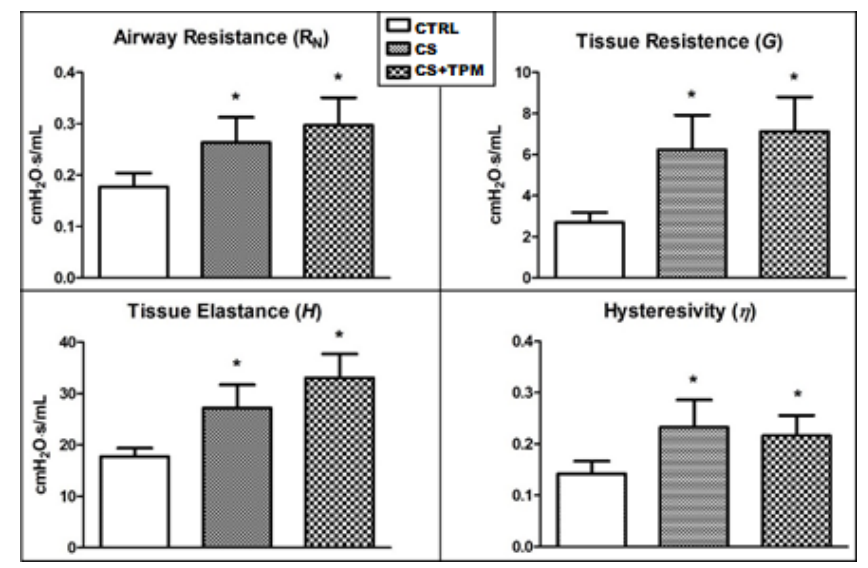

Fig. 3 Values of the variables of the constant phase model. Values for airway resistance $\left(R_{N}\right)$, tissue resistance $(G)$, tissue elastance $(H)$ and hysteresivity $(\eta)$ of the animals exposed to ambient air, CTRL group, to the cigarette smoke, CS group and to cigarette smoke and TPM from the combustion of cashew nuts shells, CS+TPM group. Values are represented by mean \pm standard deviation of the mean. * Represents statistically significant values in comparison to the control group $(p<0,05)$.

The results concerning the analysis of the volume pressure curve are presented in Figure 4. Some comparisons between the static complacency $\left(C_{S T}\right)$, estimation of inspiratory capacity $(I C)$ and PV loop area of the CTRL, CS and CS+TPM groups, presented statistically significant differences $(\mathrm{p}<0.05)$.

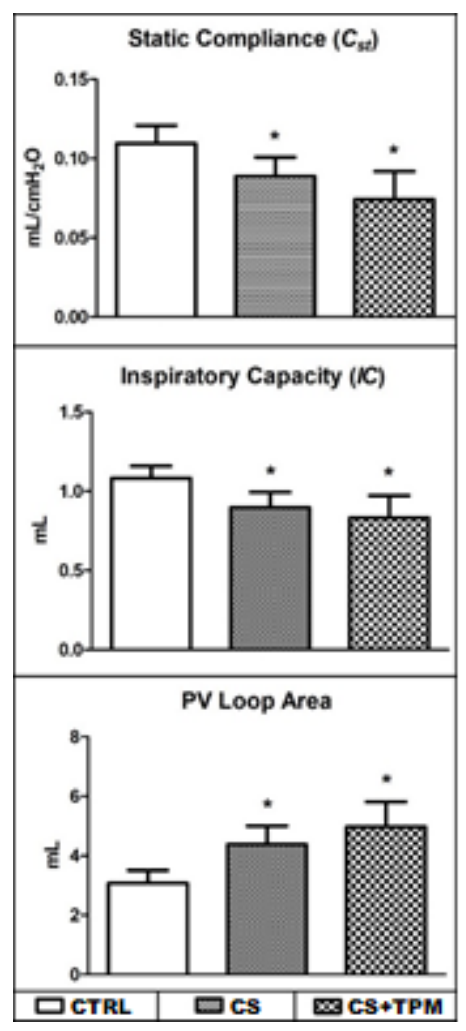

Fig. 4 Values referring to the variables collected from the PV curve. The static complacency $\left(C_{S T}\right)$, estimation of inspiratory capacity (IC) and PV loop area, of the animals exposed to ambient air, CTRL group, to the cigarette smoke, CS group, and to cigarette smoke and TPM from the combustion of cashew nuts shells, CS+TPM group. Values are represented by mean \pm standard deviation of the mean. * Represents statistically significant values in comparison to the control group $(p<0,05)$.

Figure 5 shows the variations in $\Delta R_{N}$ after administration of $\mathrm{MCh}(30 \mathrm{mg} / \mathrm{mL})$ in the groups. We observed an increase in the groups CS and CS+TPM in comparison to the CTRL group and an increase $\left(\Delta R_{N}\right)$ at several points of the groups CS and CS+TPM in comparison to the CTRL group, evidencing an airway hyperresponsiveness (AHR). 


\section{Methacholine Challenge}

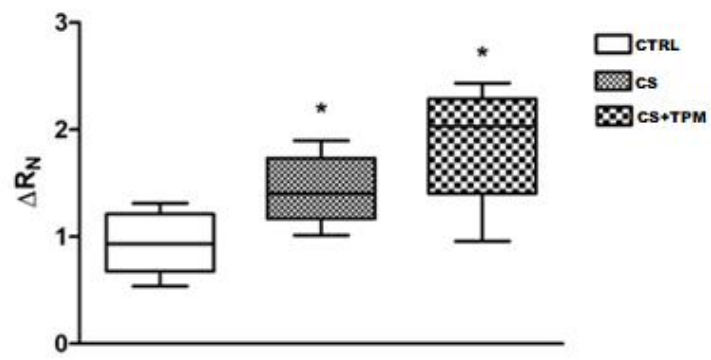

Fig. 5 Methacoline challenge as a function of number of measurements after MCh nebulization ( $30 \mathrm{mg} / \mathrm{mL}$ for $30 \mathrm{~s})$ in animals exposed to ambient air, CTRL group, to the cigarette smoke, CS group, and to cigarette smoke and TPM from the combustion of cashew nuts shells, CS+TPM group. Values are represented by mean \pm standard deviation of the mean. * Represents statistically significant values in comparison to the control group $(p<0,05)$.

Figure 6 depicts representative lung and airway (inserts) histological images of the CTRL, CS and CS+TPM groups. There was the presence of alveolar collapse, thickened septa, cellular infiltration and constricted airways (inserts) in the photomicrographs of the pulmonary parenchyma of the CS and CS+TPM groups.

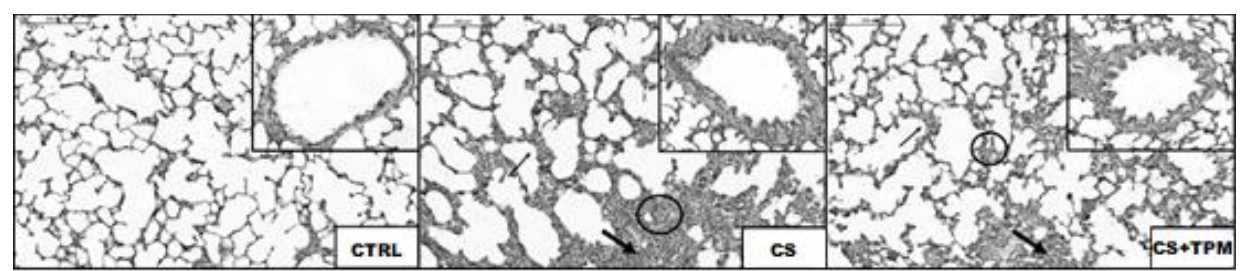

Fig. 6 Photomicrographs of lung parenchyma and airway (inserts) stained with hematoxylin-eosin of CTRL, CS and CS+TPM groups. Hin arrows: thickened septa; thick arrows: cellular infiltrate and circles: alveolar collapse.

Table 1 displays the alveolar collapse, amount of polymorphonuclear cells, mean alveolar diameter and bronchoconstriction index. We observed an increase in alveolar collapse, amount of polymorphonuclear cells, mean alveolar diameter and bronchoconstriction index of the CS and CS+TPM groups when compared to the CTRL group.

Table 1 Morphometric parameters.

\begin{tabular}{|c|c|c|c|c|}
\hline Groups & Alveolar Collapse (\%) & PMN Cells $\left(\mathbf{x 1 0}^{-3} / \mathbf{\mu m}^{\mathbf{2}}\right)$ & Mean alveolar diameter $(\boldsymbol{\mu m})$ & BCI \\
\hline CTRL & $4,77 \pm 3,06$ & $8,45 \pm 1,45$ & $37,25 \pm 3,55$ & $1,90 \pm 0,10$ \\
\hline CS & $29,85 \pm 7,30^{\mathrm{a}}$ & $23,66 \pm 2,69^{\mathrm{a}}$ & $58,08 \pm 5,14^{\mathrm{a}}$ & $2,57 \pm 0,36^{\mathrm{a}}$ \\
\hline CS+TPM & $39,91 \pm 4,74^{\mathrm{a}}$ & $25,79 \pm 3,79^{\mathrm{a}}$ & $51,43 \pm 5,84^{\mathrm{a}}$ & $2,84 \pm 0,44^{\mathrm{a}}$ \\
\hline
\end{tabular}

Values are mean \pm SD of groups CTRL, CS and CS+TPM. The data were collected in ten matched fields per mice. The CTRL group was submitted to the same procedures as the other groups, but without exposure to pollutants. In CS and CS+TPM groups, mice were were submitted to the protocol of induction to COPD by cigarette smoke. After the protocol of induction to COPD the CS+TPM group received intranasal instillation of TPM during the period of 20 days, while the CS group received intranasal instillation of saline. ${ }^{a}$ Different from CTRL group $(\mathrm{p}<0.05)$.

\section{DISCUSSION}

It is known that the environment in which the individual is inserted is relevant for the aggravation of diseases of the respiratory system (HANSEL et al., 2013). In this sense, in the attempt to simulate the exposure of people living in areas close to industrial centers or using biomass combustion for food cooking, with previous lung disease, the present study evaluated the effects of exposure to TPM by exhaust gases from CNS combustion, after the development of COPD induced by CS.

The energetic utilization of residual products from cashew processing, such as CNS, is already a reality in some industries. In particular, combustion exhaust gases from CNS promote the release of various pollutants, such as aldehydes, ketones and polycyclic aromatic hydrocarbons (PAHs), which are capable of promoting significant pulmonary changes (JOSINO et al., 2017). As well as TPM, which can easily penetrate the respiratory system and reach the pulmonary alveoli, resulting in diseases of respiratory diseases (WHO, 2005; LEWNÉ; NILS, 2007; XIAO et al., 2011), such as COPD.

The characteristics of human COPD can be induced in mice by the administration of proteases, particles and exposure to cigarette smoke. Although animal models do not perfectly replicate human COPD, prolonged exposure to cigarette smoke produces lesions consistent with the mild form of centrilobular emphysema observed in humans (WRIGHT; COSIO; CHURG, 2008).

In relation to our results, we assessed respiratory mechanics by the forced oscillation technique using a constant phase model (Figure 3), and quasi-static PV curve (Figure 4). In the constant phase model, the Newtonian resistance $\left(R_{N}\right)$ represents a good estimate of the total central airway resistance, ${ }^{14}$ and tissue resistance $(G)$ and tissue elastance $(H)$ are related to the intrinsic 
properties of the tissue, while hysteresivity $(\eta)$ correlates with the degree of heterogeneity in lung ventilation (BATES, 2009; FREDBERG; STAMENOVIC, 1989).

In the quasi-static PV curve, the static compliance $\left(C_{S T}\right)$ indirectly measures the degree of lung tissue distensibility, and estimate of inspiratory capacity $(I C)$ quantifies the volume of air received by the lungs up to a pressure of $30 \mathrm{cmH}_{2} \mathrm{O}, \mathrm{while}_{\mathrm{PV}}$ loop area provides an estimate of the amount of atelectasis (airspace closure) that existed before the PV loop manoeuvre (WEST, 2012). To estimate $I C$ and $C_{S T}$, the pressure and volume data were measured in the upper flatter portion of the expiratory limb of the PV curve.

The increase in the value of $R_{N}$ in groups CS and CS+TPM may represent greater narrowing of airway lumen or increased stiffness of smooth muscle of the airways in this groups compared to the CTRL group (SERRA et al., 2017). Our findings of histological analysis (Figure 6, insert) and lung parenchymal morphometry (Table 1, BCI) confirming narrower airways. In addition, the destruction of the alveolar wall, present in pulmonary emphysema (CS and CS+TPM groups), causes a distortion in the pulmonary parenchyma, reducing the tension that generates in the airway wall (BARNES; SHAPIRO; PAUWELS, 2003), causing the decrease of its lumen and consequent increase in the $R_{N}$.

Tissue resistance $(G)$ and tissue elastance $(H)$ are related to the intrinsic properties of the tissue. The increase of these parameters in the CS and CS+TPM groups may be related might be the change in tissue rheological properties (BATES, 2009). That could result from thickening of the alveolar septum and presence of atelectatic areas, as observed in our histological analysis (Figure 6), increased amount of collapsed alveoli, reduced alveolar diameter, and the increased number of polymorphonuclear cells (Table 1). The ratio of the dissipative $(G)$ to the elastic $(H)$ component of overall energy is named hysteresivity $(\eta)$, and correlates with the degree of heterogeneity in lung ventilation (BATES, 2009; FREDBERG; STAMENOVIC, 1989). Therefore, the increase in $\eta$ in the CS and CS+TPM groups may be related to the increase in ventilatory heterogeneities, probably caused by the changes in the $R_{N}$ (BATES, 2009).

In relation to the analysis of the quasi-static PV curve (Figure 4), the chronic imbalance, influenced by smoking, provides high activity of proteases, low amounts of antiproteases, destruction of the extracellular matrix (ECM) and consequently increase of the mean alveolar diameter (SHAPIRO; INGENITO, 2005). With this, we would expect to see an increase in $C_{S T}$ and $C I$ in CS and CS+TPM groups, as a consequence of the loss of elastic recoil determined by the fibers of the pulmonary parenchyma.

However, our findings did not identify this behavior. Similar results were found by Kennedy-Feitosa and collaborators (2016). This fact can be explained due to parameters such as $C_{S T}$ and $C I$ are not commonly used in animal model studies to characterize COPD. For this, the mean alveolar diameter is used, being increased in both groups (Table 1). The increase in PV loop area in groups CS and CS+TPM, might be attributed to tissue changes (alveolar collapse, presence of PMN cells - Table 1) and possibly to a surfactant-associated mechanism (MÜLLER; SEIFART; BARTH, 1998).

Regarding pulmonary response to challenge with MCh (Figure 5), there was a statistically significant increase in CS and CS+TPM airway resistance compared to the CTRL group (Figure 3), evidencing a hyperresponsiveness of the smooth muscle of the airways. Hyperresponsiveness can also be attributed to the presence of inflammatory processes in the airways of these animals, where similar studies have reported airway hyperresponsiveness following exposure to cigarette smoke (LO et al., 2018) or pollutants (SERRA et al., 2017).

In order to analyze our hypothesis that the acute exposure to atmospheric pollutants, specifically TPM from the CNS combustion, in individuals of susceptible groups (COPD), can exacerbate the harmful effects of this pollutant in the respiratory system, we compared the mechanics data of the CS and CS+TPM groups with the CTRL group.

Regarding the parameters of the constant phase model, we observed in the CS group an increase of $33.2 \%, 56.7 \%$ and $34.7 \%$ in the values of $R_{N}, G$ and $H$, respectively. In the CS+TPM group, this increase was $40.7 \%, 62.2 \%$ and $46.3 \%$, in the $R_{N}, G$ e $H$, respectively. Regarding the parameters of the quasi-static PV curve, we observed in the CS group an decrease of $23.2 \%$ and $29.8 \%$ in the values of $C_{S T}$ and $I C$, and a $20.7 \%$ increase in the value of PV Loop area. In the CS+TPM group, this decrease was $47.3 \%$ and $38.1 \%$ in the $C_{S T}$ e $I C$, and a $30.1 \%$ increase in the value of $P V$ Loop area.

These results demonstrate the lung injury of the animals caused by exposure to cigarette smoke (CS group), but that this injury is greater when associated with exposure to TPM from the combustion of CNS (CS+TPM group). Evidenciating the harmful effects caused by the exposure that this pollutant, from the combustion of a residual biomass, causes in the respiratory system of animals with respiratory pathology.

\section{CONCLUSION}

Despite the encouragement to use renewable resources to the detriment of fossil fuel derivatives, care must be taken with the combustion of residual biomass. The increasing use of this biofuel in industries, craft centers and homes, warns of exposure to exhaust gases. The health of the surrounding population may be harmful, especially to those with pre-existing respiratory disease. These, because they have low resilience, are more susceptible to damages caused by exposure to pollutants. The present paper serves as an alert for government agencies to review some parameters of atmospheric emissions.

\section{ACKNOWLEDGEMENT}

This study was financed in part by the Coordenação de Aperfeiçoamento de Pessoal de Nível Superior - Brasil (CAPES) Finance Code 001. 
Citation: Fladimir de Lima Gondim, et al Effects of Exposure to Total Particulate Matter of Cashew Nuts Shell in the Respiratory System of Mice with Chronic Obstructive Pulmonary Disease. Australian Journal of Basic and Applied Sciences, 13(1): 71-79. DOI: 10.22587/ajbas.2019.13.1.9

Barnes, P.J., Shapiro, S.D., Pauwels, R.A., 2003. Chronic obstructive pulmonary disease: molecular and cellularmechanisms. European Respiratory Journal, 4:672-688. DOI: 10.1183/09031936.03.00040703

Bates, J.H., 2009. Lung mechanics: an inverse modeling approach. ed. Cambridge University Press.

Dockery, C.A., Hueckel-Weng, R., Birbaumer, N and Plewnia, C., 2009. Enhancement of planning ability by transcranial direct current stimulation. Journal Neuroscience, 22:7271-7277. DOI: 10.1523/JNEUROSCI.0065-09.2009

Donaldson, K., Macnee, W., 2001. Potential mechanisms of adverse pulmonary and cardiovascular effects of particulate air pollution $\left(\mathrm{PM}_{10}\right)$. International Journal of Hygiene and Environmental Health, 203(5-6):411-415. DOI: 10.1078/1438-463900059

Elwood, P., Galante, J., Pickering, J., Palmer, S., Bayer, A., Ben-Shlomo, Y and Gallacher. J., 2013. Healthy lifestyles reduce the incidence of chronic diseases and dementia: evidence from the Caerphilly cohort study. PloS one, 8(12):1-7. DOI: 10.1371/journal.pone.0081877

Ezzati, M., and Kammen, D. M, 2002. The health impacts of exposure to indoor air pollution from solid fuels in developing countries: knowledge, gaps, and data needs. Environmental health perspectives, 110(11):1057. DOI: 10.1289/ehp.021101057

Fredberg, J.J., Stamenovic, D., 1989. On the imperfect elasticity of lung tissue. Journal of applied physiology, 6:2408-2419. DOI: 10.1152/jappl.1989.67.6.2408

Global strategy for the diagnosis (GOLD) [homepage on the Internet]. Management and Prevention of COPD, Global Initiative for Chronic Obstructive Lung Disease, 2018 [update 2018 Feb 16]. Retrieved from: http://goldcopd.org

Hansel, N.N., Mccormack, M.C., Belli, A.J., Matsui, E.C., Peng, R.D., Aloe, C., Paulin, L., Williams, D.L., Diette, G.B., Bre ysse, P.N., 2013. In-Home Air Pollution Is Linked to Respiratory Morbidity in Former Smokers with Chronic Obstructive Pulmonary Disease. Am J RespirCrit Care Med, 10:1085-1090. DOI: 10.1164/rccm.201211-1987OC

Hantos, Z., Daroczy, B., Suki, B., Nagy, S., Fredberg, J.J., 1992. Input impedance and peripheral inhomogeneity of dog lungs. Journal of applied physiology, 72(1):168-178. DOI: 10.1152/jappl.1992.72.1.168

Hirai, T., McKeown, K.A., Gomes, R.F.M., Bates, J.H.T., 1999. Effects of lung volume on lung and chest wall mechanics in rats. Journal of Applied Physiology, 86(1):16-21. DOI: 10.1152/jappl.1999.86.1.16

Josino, J.B., Serra, D.S., Gomes, M.D.M., Araújo, R.S., de Oliveira, M.L.M., Cavalcante, F.S.A., 2017. Changes of respiratory system in mice exposed to PM4.0 or TSP from exhaust gases of combustion of cashew nut shell. Environmental toxicology and pharmacology, 56:1-9. DOI: 10.1016/j.etap.2017.08.020

Kennedy-Feitosa, E., Okuro, R.T., Ribeiro, V.P, Lanzetti, M., Barroso, M.V., Zin, W.A and Valenca, S.S., 2016. Eucalyptol attenuates cigarette smoke-induced acute lung inflammation and oxidative stress in the mouse. Pulmonary pharmacology \& therapeutics, 41:11-18. DOI: 10.1016/j.pupt.2016.09.004

Knudsen, L., Weibel, E.R., Gundersen, H.J.G., Weinstein, F.V., Ochs, M., 2010, Assessment of air space size characteristics by intercept (chord) measurement: an accurate and efcient stereological approach. J Appl Physiol, 108(2):412-421. DOI: 10.1152/japplphysiol.01100.2009

Lee, H., Jung, K.H., Lee, H., Park, S., Choi, W. and Bae, H., 2015. Casticin, an active compound isolated from Vitex Fructus, ameliorates the cigarette smoke-induced acute lung inflammatory response in a murine model. International immunopharmacology, 28(2):1097-1101. DOI: 10.1016/j.intimp.2015.07.041

Lewné, M., Nils, P., Per, G., 2007. Exposure to Particles, Elemental Carbon and Nitrogen Dioxide in Workers Exposed to Motor Exhaust. Anals of Work Exposure and Health, 51(8):693-701. DOI: 10.1093/annhyg/mem046

Lo, C.Y., Huang, H.Y., He, J.R., Huang, T.T., Heh, C.C., Sheng, T.F., Wang, C.H., 2018. Increased matrix metalloproteinase-9 to tissue inhibitor of metalloproteinase-1 ratio in smokers with airway hyperresponsiveness and accelerated lung function decline. International journal of chronic obstructive pulmonary disease, 13:1135-1144. DOI: 10.2147/COPD.S161257

Lopez, A. D., Mathers, C. D., Ezzati, M., Jamison, D. T., \& Murray, C. J. (Eds.), 2006. Global burden of disease and risk factors. The World Bank. DOI: 10.1016/S0140-6736(06)68770-9

Maatz, L,F., Wood, G.J.A., Rivero, D.H.R.F., Saldiva, P.H.N., 2009. Tracheal instillation of urban PM2.5 suspension promotes acute cardiac polarization changes in rats. Brazilian journal of medical and biological research, 42(2):207-13. DOI: 10.1590/S0100-879X2009000200009

Mainali, P., Pant, S., Rodriguez, A.P., Deshmukh, A and Mehta, J,L., 2015. Tobacco and Cardiovascular Health. Cardiovasc Toxicol, (15):107-116. DOI: 10.1007/s12012-014-9280-0

Müller, B., Seifart, C., Barth, P.J., 1998. Effect of air pollutants on the pulmonary surfactant system. European journal of clinical investigation, 28(9):762-777. DOI: 10.1046/j.1365- 362.1998.00342.x

Nakamura, M., Wada, H., Honda, K., Nakamoto, K., Inui, T., Sada, M. and Kurai, D., 2015. Clarithromycin ameliorates pulmonary inflammation induced by short term cigarette smoke exposure in mice. Pulmonary pharmacology \& therapeutics, (35):60-66. DOI: 10.1016/j.pupt.2015.09.005

Petrusca, D.N., Van Demark, M., Gu, Y., Justice, M.J., Rogozea, A., Hubbard, W,C and Petrache, I., 2014. Smoking exposure induces human lung endothelial cell adaptation to apoptotic stress. American journal of respiratory cell and molecular biology, 50(3):513-525. DOI: 10.1165/rcmb.2013-0023OC

Salazar, E., Knowles, J.H., 1964. An analysis of pressure-volume characteristics of the lungs. Journal of applied physiology, 19(1): 97-104. DOI: 10.1152/jappl.1964.19.1.97

Serra, D.S., Evangelista, J.S.A.M., Zin, W.A., Leal-Cardoso, J.H., Cavalcante, F.S.Á., 2017. Changes in rat respiratory system produced by exposure to exhaust gases of combustion of glycerol. Respiratory physiology \& neurobiology, 242:80-85. DOI: 10.1016/j.resp.2017.04.001 
Shapiro, S.D., Ingenito, E.P,. 2005. The pathogenesis of chronic obstructive pulmonary disease: advances in the past 100 years. American Journal of Respiratory Cell and Molecular Biology, 32(5):367-372. DOI: 10.1165/rcmb.F296

Valença, S.S., Bezerra, F.S., Romana-Souza, B., Paiva, R.O., Costa, A.M., Porto, L.C., 2008. Supplementation with vitamins C and E improves mice lung repair. Journal of Nutritional Biochemistry, 19(9): 604-611. DOI: 10.1016/j.jnutbio.2007.08.004

Weibel, E.R., 1990. Morphometry: stereological theory and practical methods. In: Gil J, editor. Models of lung disease: microscopy and structural methods. New York: Marcel Dekker; 199-247.

West, J.B., 2012. Respiratory physiology: the essentials. In: Lippincott Williams \& Wilkins. ed. Wolters Kluwer.

World health organization [homepage on the Internet], 2005 [update 2016 Apr 16]. Who air quality guidelines global: report on a working group meeting. Retrieved from: http://www.euro.who.int/_data/assets/pdf_file/0008/147851/E87950.pdf

Wright, J.L, Cosio, M., Churg, A., 2008. Animals models of human lung disease. Am. J. Physiol. Lung. Cell. Mol. Physiol, 295:115. DOI: $10.1586 /$ ers. 10.68

Xiao, Z.M., Zhang, Y.F., Hong, S.M., Bi, X.H., Jiao, L., Feng, Y.C., 2011. Estimation of the Main Factors Influencing Haze, Based on a Long-term Monitoring Campaign in Hangzhou, China. Aerosol And Air Quality Research, 11(1):873-882. DOI:10.4209/aaqr.2011.04.0052

Xue, Z., Zhang, L., Liu, Y., Gunst, S.J., Tepper, R.S., 2008. Chronic inflation of ferret lungs with CPAP reduces airway smooth muscle contractility in vivo and in vitro. J Appl Physiol, 104:610-15. DOI: 10.1152/japplphysiol.00241.2007 